\title{
Evaluation and Classification of Power Quality Disturbances Based on Discrete Wavelet Transform and Artificial Neural Networks
}

\author{
Saeed Alshahrani \\ Maysam Abbod \\ School of Engineering, Design
Physical Sciences, Brunel
University London \\ E-mail: \\ saeed.alshahrani@brunel.ac.uk
}

\author{
Basem Alamri \\ School of Engineering, Design
Physical Sciences, Brunel
University London \\ E-mail: \\ basem.alamri@brunel.ac.uk
}

\author{
Gareth Taylor
}

School of Engineering, Design an Physical Sciences, Brunel

University London

E-mail:

Gareth.Taylor@brunel.ac.uk

\begin{abstract}
In this paper, detection method and classification technique of power quality disturbances is presented. Due to the increase of nonlinear load recently, it becomes an essential requirement to insure high level of power supply and efficient commotional consuming. Wavelet Transform represents a powerful mathematical platform which is needed especially at non-stationary situations. Disturbances are fed into wavelets to filter, detect and extract its features at different frequencies. Training of features extracted by WT is done using artificial neural networks ANN to classify power quality disturbances.
\end{abstract}

Index Terms--Power Quality, Disturbances, Feature Extraction, Discrete Wavelet Transform, Classification, Artificial Neural Networks.

\section{INTRODUCTION}

The increasing applications of nonlinear loads which come from power electronics devices have made the power quality problems a critical issue more than ever. Power delivery is expected to be received at rated sinusoidal voltage and current without distortion to customers. An efficient control of power quality problems is highly dependent on their accurate measurements and effective detection in time which makes challenging issues for researchers and engineers [1]. The definitions of power components in IEEE standard 14592010 are based on Fourier Transform (FT)[2]. Unfortunately, FT and is not a sufficient method for non-stationary situations [3]. FT is unable to resolve fluctuated information when the time is limited [4]. Moreover, Fast Fourier Transform FFT can give accurate results for stationary waveforms but, it produces large errors for power systems for non-stationary waveforms [5]. Therefore, it is essential to develop an alternative approach for measuring power quantities and evaluating power quality.

One of the powerful methods to quantify and analyse power quantities is wavelet transform (WT). It gives a representation for power signals in both time and frequency domain. WT has been involved in this field for disturbances

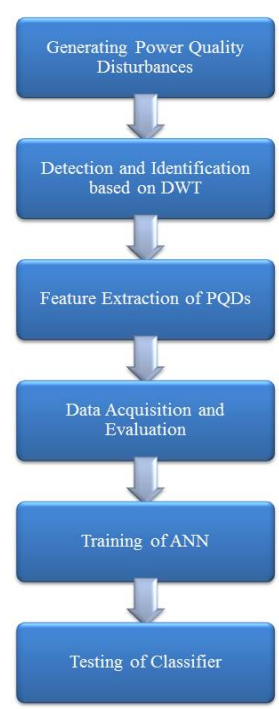

Fig. 1. The Structure of the classification system technique

associated with power quality [6]. Originally, WT has two categories called discrete wavelet transform (DWT) and continuous wavelet transform (CWT) [7]. Recently, WT has anther derivative has been implemented successfully for the definitions of power quantities according to IEEE std 14592010 which is called stationary wavelet transform SWT [8]. Nevertheless, Wavelet Packet Transform (WPT) has been introduced for Power Quality Indices in [9]. The key factor related to the use of wavelet mother is choosing the suitable wavelet where it helps with the increase of computational cost.

For solid understanding, it is required to classify features extracted from power signal disturbances to enhance power quality. To ensure better performance of any detection method, it is essential to develop classification techniques [10]. Artificial intelligent techniques have proved its ability for classifications purposes where it include training, learning, prediction and problem solving as defined in [11]. 
Artificial Neural Networks (ANN) represents a capable technique especially in classification, pattern matching and data analysis [12]. It is implemented primarily for classifying power quality events as proposed in [13]. Authors have proposed an automatic localisation method for various power quality faults in [14]. An approach of identification of harmonics source is presented in [15]. A method has been proposed for fault detection in transmission lines using ANN based on wavelet in [16]. A proposed classification system for power quality events based on S-transform and probabilistic neural networks in [17].

\section{DisCRETE WAVELET TRANSFORM}

The choice of detecting and identifying power quality disturbances using wavelet transform is an appropriate due its capability to handle non-stationary situations [18]. It proves effectively analysing the distorted signals in time-frequency domain as it is defined in [19]. It can be describers mathematically as in [20] as follows:

$$
f(x)=\sum_{i j} a_{i, j} \psi_{i, j}(x)
$$

where $i$ and $j$ represent the integer values and $\psi_{i, j}(x)$ stands for wavelet expansion functions. $a_{i j}$ Stands for the two coefficients of discrete wavelet transform (DWT) of $f(x)$. These coefficients have the formula:

$$
a_{i, j}=\int_{-\infty}^{+\infty} f(x) \psi_{i, j}(x)
$$

where $\psi \psi_{\mathrm{i}, \mathrm{j}}(\mathrm{x})$ represent the mother wavelet and can gain its parameters through:

$$
\psi_{i, j}(x)=2^{-i / 2} \psi\left(2^{-j} x-j\right)
$$

where $i$ represent the scaling parameter in wavelet and $j$ for the translation one. For multiresolution satisfaction, the different of two scale equation is given as:

$$
\phi(\mathrm{x})=\sqrt{2} \sum_{\mathrm{k}} \mathrm{h}(\mathrm{k}) \phi(2 \mathrm{x}-\mathrm{k})
$$

where $h(k)$ gives the wavelet function a unique value by satisfying wavelet conditions and $\phi(x)$ is scaling function which has a relation with mother of wavelet as follows:

$$
\psi(x)=\sqrt{2} \sum_{k} g(k) \phi(2 x-k)
$$

where $\mathrm{h}$ in (4) and $\mathrm{g}$ in (5) can be considered as filters of wavelet of low-pass filter and high pass filter respectively. From all the above equation, the $\mathrm{j}$ wavelet value can be determined as:

$$
f_{0}(x)=\sum_{k} a_{0, k} \phi_{0, k}(k)=\sum_{k} a_{J+1, k} \phi_{J+1, k}(x)+\sum_{j=0}^{J} d_{j+1, k} \psi_{j+1, k}(x)
$$

where $a_{0, k}, a_{J+1, k}, d_{j+1, k}$ are the coefficients at scale $\mathrm{j}+1$ and can be determined under the condition of the availability of scale $j$ as follow:

$$
\begin{aligned}
& a_{j+1, n}=\sum_{k} a_{j, k} h(k-2 n) \\
& d_{j+1, n}=\sum_{k} a_{j, k} g(k-2 n)
\end{aligned}
$$

where $a_{j+1, n}$ is the approximation coefficient and $d_{j+1, n}$ is the detailed one at scale $j+1$ and they are defined.

Figure 2 shows the decompensation analysis of power quality disturbances using discrete wavelet transform DWT in this work for each disturbance

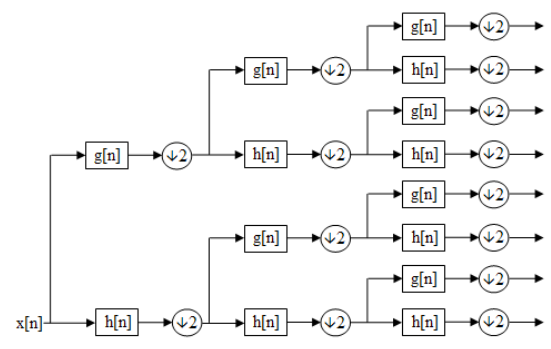

Fig. 2. Decomposition of distorted signal based on DWT.

\section{Detection And IDENTIFICATION}

In this section, a normal sine wave with frequency of $50 \mathrm{~Hz}$ is generated as well as nine power quality disturbances (sag,

\begin{tabular}{|c|c|c|}
\hline PQDs & Equations Models & Parameters \\
\hline Pure Sine & $f(t)=A \sin (\omega t)$ & $A=1.0 f=50 \mathrm{~Hz}$ \\
\hline Sag & $f(t)=A\left(1-\alpha\left(u\left(t-t_{1}\right)-u\left(t-t_{2}\right)\right)\right) \sin (\omega t)$ & $0.1<\alpha<0.9$ \\
\hline Swell & $f(t)=A\left(1+\alpha\left(u\left(t-t_{1}\right)-u\left(t-t_{2}\right)\right)\right) \sin (\omega t)$ & $0.1<\alpha<0.8$ \\
\hline Harmonics & $f(t)=A \sin (\omega t)+\alpha_{3} \sin (3 \omega t)+\alpha_{5} \sin (5 \omega t)$ & $\begin{array}{l}0.1<\alpha_{3}<0.9 \\
0.1<\alpha_{5}<0.9\end{array}$ \\
\hline Interruption & $f(t)=A\left(1-\alpha\left(u\left(t-t_{1}\right)-u\left(t-t_{2}\right)\right)\right) \sin (\omega t)$ & $0.9<\alpha<1.0$ \\
\hline Flicker & $f(t)=A \sin (\omega t)(1+\beta \sin (\gamma \omega t))$ & $\begin{array}{l}0.1 \leq \beta \leq 0.2 \\
0.1 \leq \gamma \leq 0.2\end{array}$ \\
\hline $\begin{array}{l}\text { High frequency } \\
\text { transient }\end{array}$ & $\left.f(t)=A \sin (\omega t)+\alpha e^{-t / \lambda} \sin (b \omega t)\right)$ & $\begin{array}{r}20 \leq b \leq 80 \\
0.1 \leq \lambda \leq 0.2 \\
0.1 \leq \alpha \leq 0.9\end{array}$ \\
\hline Low frequency & $\left.f(t)=A \sin (\omega t)+\alpha e^{-t / \lambda} \sin (b \omega t)\right)$ & $5 \leq b \leq 20$ \\
\hline
\end{tabular}
swell, harmonics, interruption, flicker, high frequency transient, low frequency transient, sag with harmonics and swell with harmonics). These disturbances are generated according to their parametric equations [21] as shown in Table I and Figure 3 shows the output of generated models.

$$
\text { TABLE I }
$$

MODELLING OF POWER QUALITY AND ITS PARAMETERS 
This article has been accepted for publication in Proceedings of the Universities Power Engineering Conference (UPEC 2015), Stoke on Trent, (1-4 September 2015), but has not been fully edited. Content may change prior to final publication. Citation information: DOI 10.1109/UPEC.2015.7339928, 2015 50th International Universities Power Engineering Conference (UPEC)

\begin{tabular}{|l|c|c|}
\hline transient & & $\begin{array}{c}0.1 \leq \lambda \leq 0.2 \\
0.1 \leq \alpha \leq 0.9\end{array}$ \\
\hline Sag with & $f(t)=A\left(1-\alpha\left(u\left(t-t_{1}\right)-u\left(t-t_{2}\right)\right)\right)$ & $0.1<\alpha<0.9$ \\
harmonics & $\left.\left(\sin (\omega t)+\alpha_{3} \sin (3 \omega t)+\alpha_{5} \sin (5 \omega t)\right)\right)$ & $0.05<\alpha_{3}<0.15$ \\
& & $0.05<\alpha_{5}<0.15$ \\
\hline Swell with & $f(t)=A\left(1+\alpha\left(u\left(t-t_{1}\right)-u\left(t-t_{2}\right)\right)\right)$ & $0.1<\alpha<0.8$ \\
harmonics & $\left.\left(\sin (\omega t)+\alpha_{3} \sin (3 \omega t)+\alpha_{5} \sin (5 \omega t)\right)\right)$ & $0.05<\alpha_{3}<0.15$ \\
& & $0.05<\alpha_{5}<0.15$ \\
\hline
\end{tabular}
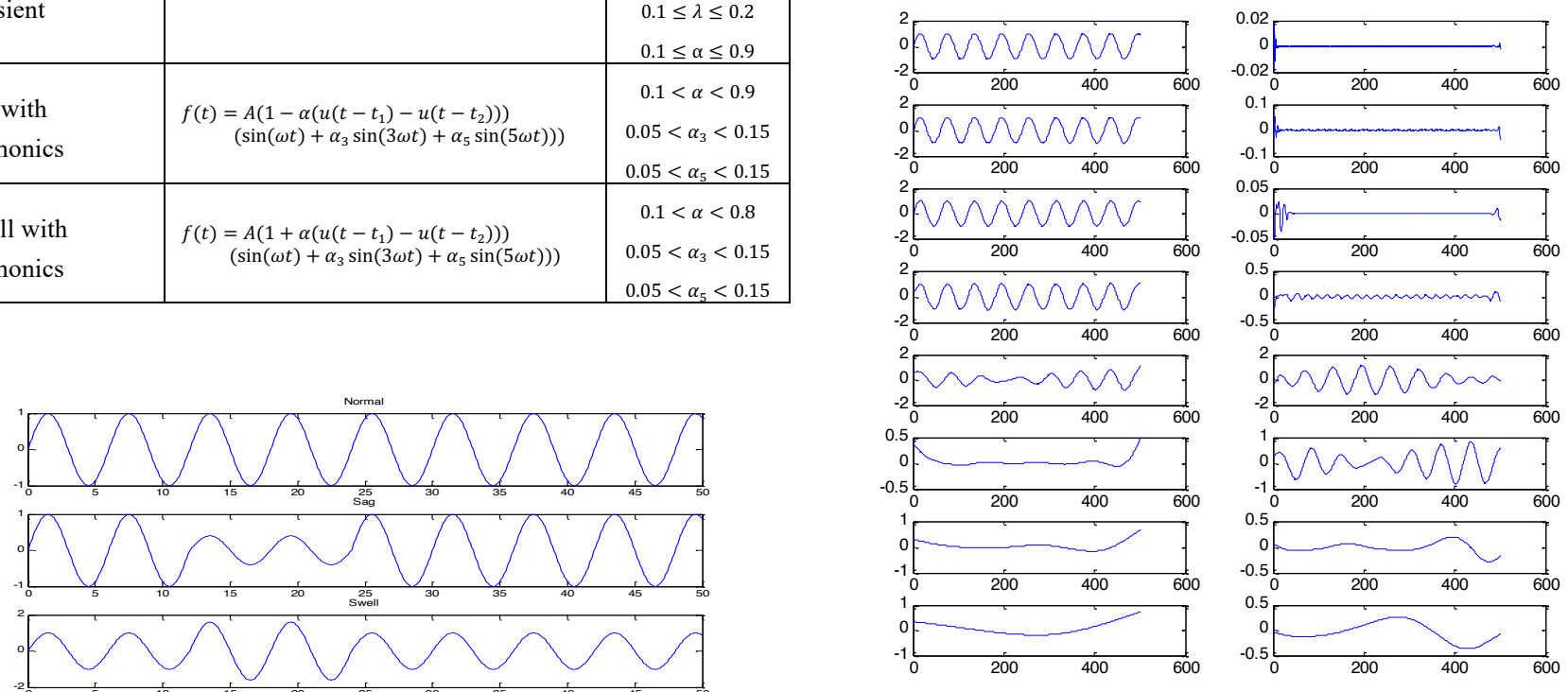

Fig. 4. Pure voltage signal and Features Extraction based on DWT.
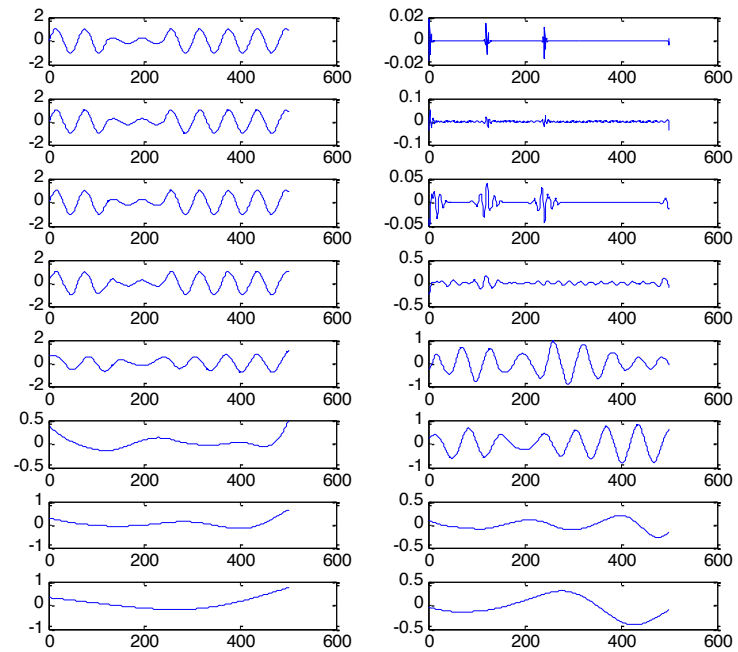

Fig. 5. Voltage sag signal and Features Extraction based on DWT.

Fig. 3. Signals generated of power quality disturbances.

\section{Feature Extraction}

The goal of extraction for each of power quality disturbances is to transform the original distorted signal from its time domain into its energy form. The energy of any type of these events is the key factor for classification. Each one PQDs generated are decomposed into 8 levels and the results for selected PQDs as shown in Figures 4, 5, 6, 7, 8, and 9. 

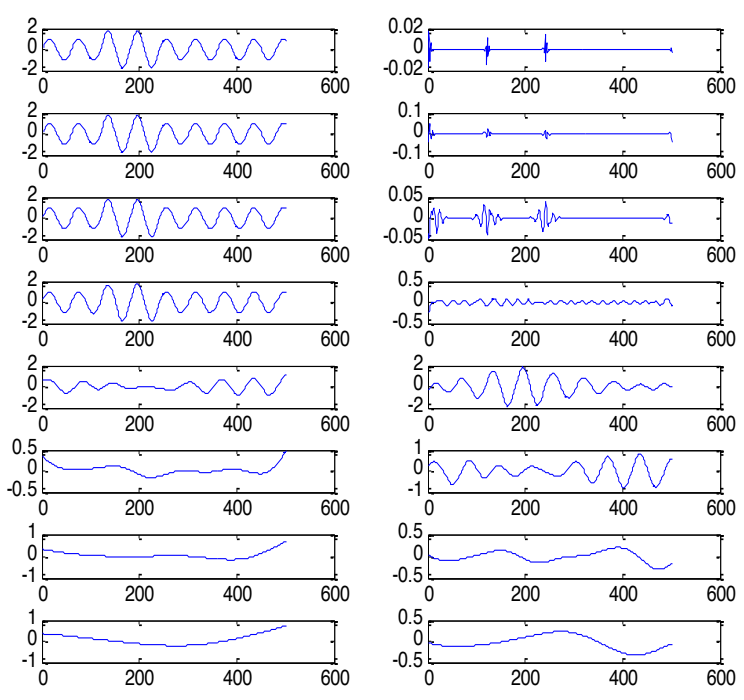

Fig. 6. Voltage swell signal and Features Extraction based on DWT.
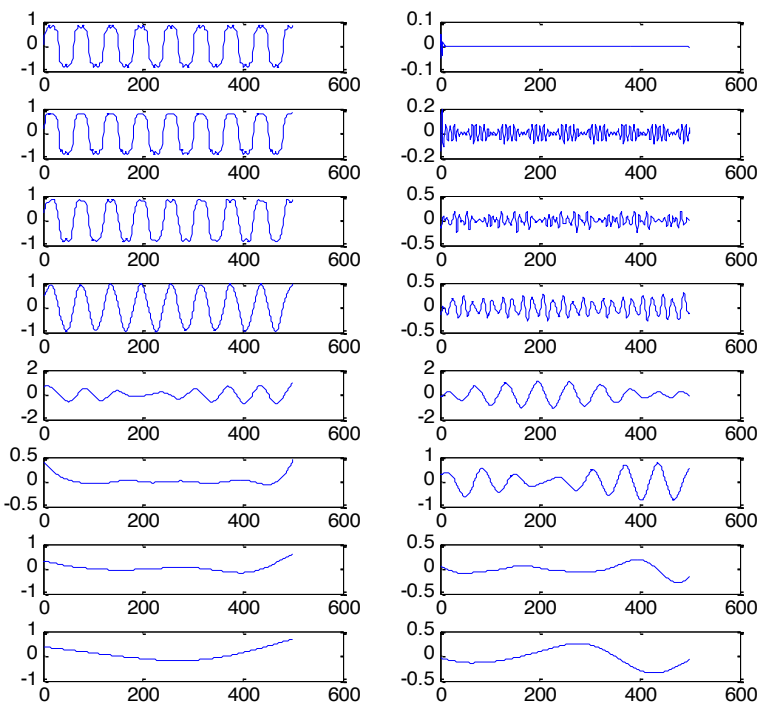

Fig. 7. Voltage Harmonics signal and Features Extraction based on DWT.
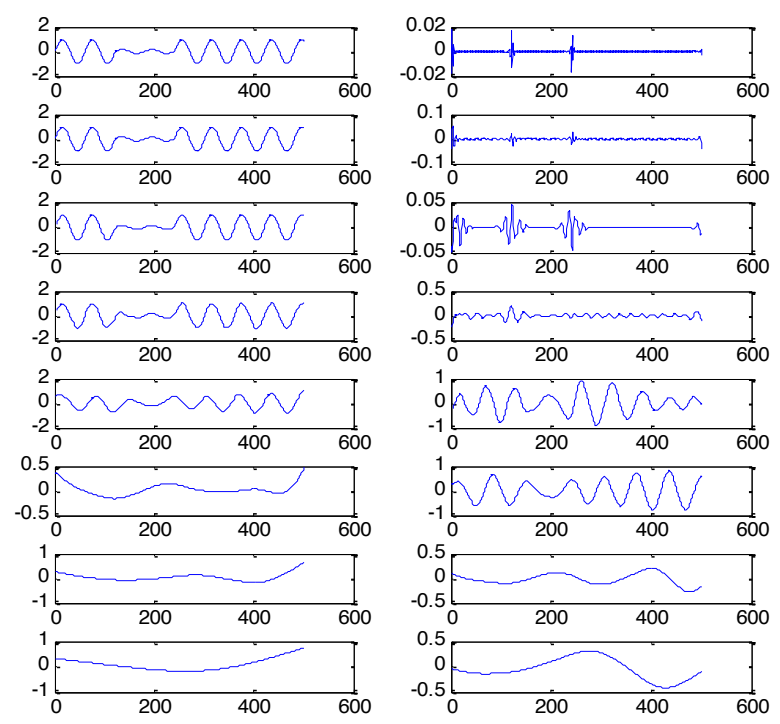

Fig. 8. Voltage interruption signal and Features Extraction based on DWT
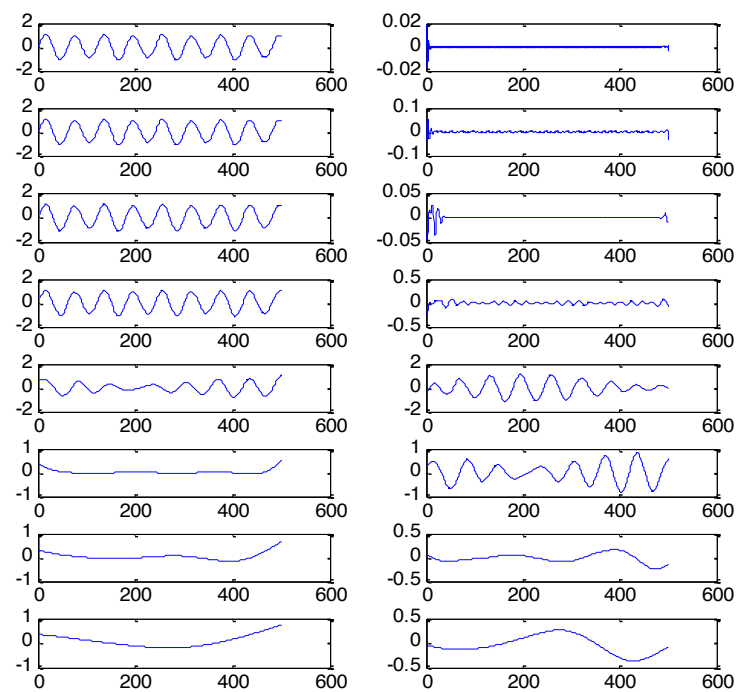

Fig. 9. Voltage flicker signal and Features Extraction based on DWT.

\section{Classification System TEChNiQue}

In order to evaluate the performance of the extraction method, a classification system is needed. Classification techniques measure the efficiency by training and testing the data extracted from power quality disturbances generated. In this study artificial neural networks (ANN) was implemented to classify power quality disturbances where each one of these events has a classification neural.

The major advantage of this technique is network learning. Hence, results of features extracted of disturbances are fed to ANN as inputs. Then, through learning phenomena process for results, it can solve problems attached to data and then solve other learned results. The operational principle of ANN stands on manipulating the inputs with weights and then computing results by mathematical model to determine the activation of the neural as shown in Figure 10. The outputs of 
This article has been accepted for publication in Proceedings of the Universities Power Engineering Conference (UPEC 2015), Stoke on Trent, (1-4 September 2015), but has not been fully edited. Content may change prior to final publication. Citation information: DOI 10.1109/UPEC.2015.7339928, 2015 50th International Universities Power Engineering Conference (UPEC)

are then calculated by anther mathematical model to initiate a structure if rules to classify different new inputs.

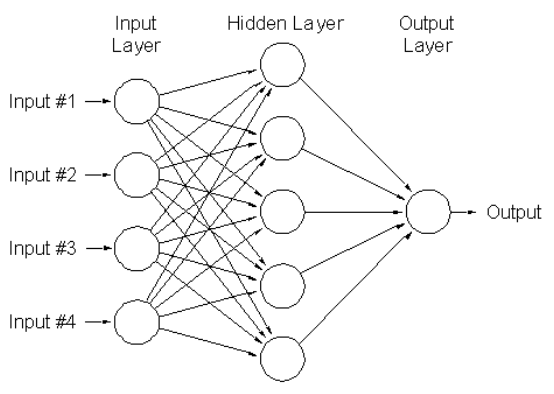

Fig. 10. The Scheme of ANN.

In this study, three stages of training the data through ANN facilities. First, data of disturbances features are fed to ANN for essential training according to pattern recognition of inputs. Second, data validation by measuring the network efficiency. Third, testing the accuracy to ensure the best performance of the neural.

\section{Results AND Discussions}

In order to prove the accuracy and the efficiency of the classifier, various power quality disturbances signals were generated by their parametrical equations. Features extractions have been done using discrete wavelet transform DWT as discussed in IV power quality problems.

Thereafter, each of these disturbances has been investigated by 8 multi-level of DWT decompensation. 10 types of power quality disturbances were studied with taking into account their characteristics: magnitude and frequency according to IEEE standard requirements [22].

Signals are then used for training and classification by ANN. 40 variables results of 10 types of disturbances (normal and others PQDs) were implemented in the neural taking into account that each of these data has 8 multi-level of extraction which gave a database of 3200 inputs.

One and two hidden layers from 5 to 50 neurons were used to investigate the best performance of training. Table II shows the accuracy of one hidden layer the success percentage of each disturbance. Table III shows the accuracy of two hidden layers.

TABLE II

\begin{tabular}{|c|l|c|}
\hline \multicolumn{2}{|c|}{ CLASSIFICATION ACCURACY OF ANN WITH ONE HIDDEN LAYER } \\
\hline Neural & PQDs & Accuracy Rate (\%) \\
\hline C1 & Normal & 90.786 \\
\hline C2 & Voltage Sag & 90.800 \\
\hline C3 & Voltage Swell & 90.657 \\
\hline C4 & harmonics & 91.157 \\
\hline C5 & interruption & 91.104 \\
\hline C6 & flicker & 90.786 \\
\hline C7 & high frequency transient & 90.714 \\
\hline C8 & low frequency transient & 90.914 \\
\hline
\end{tabular}

\begin{tabular}{|c|l|c|}
\hline C9 & sag with harmonics & 90.801 \\
\hline C10 & swell with harmonics & 90.314 \\
\hline
\end{tabular}

TABLE III

ClassificAtion ACCURACy OF ANN With Two HidDEN LAYERS

\begin{tabular}{|c|l|c|}
\hline Neural & PQDs & Accuracy Rate (\%) \\
\hline C11 & Normal & 91.271 \\
\hline C12 & Voltage Sag & 91.071 \\
\hline C13 & Voltage Swell & 90.829 \\
\hline C14 & harmonics & 91.114 \\
\hline C15 & interruption & 91.057 \\
\hline C16 & flicker & 90.771 \\
\hline C17 & high frequency transient & 90.414 \\
\hline C18 & low frequency transient & 90.603 \\
\hline C19 & sag with harmonics & 90.657 \\
\hline C20 & swell with harmonics & 90.671 \\
\hline
\end{tabular}

\section{CONCLUSIONS}

Detection and identification of power quality disturbances methods was generated successfully. Based on discrete wavelet transform DWT it has been ensured that wavelet transform can overcome Fourier transform limits with nonstationary disturbances which are mentioned in this paper. Thereafter, Features of these disturbances were extracted to 8 levels and energy of each level was calculated and used for building the data needed for the classifier.

Training of ANN was implemented and database of 3200 signals were randomly generated with different variation. Results were investigated, trained and tested to evaluate the classification system technique. As a result, the accuracy of the power quality disturbances classification were more than $90 \%$ for all the cases which indicate the performance efficiency of ANN classifier for power quality disturbances.

\section{REFERENCES}

[1] J. Arrillaga, M. H. Bollen and N. R. Watson, "Power quality following deregulation," Proc IEEE, vol. 88, pp. 246-261, 2000.

[2] IEEE Standard Definitions for the Measurement of Electric Power Quantities Under Sinusoidal, Nonsinusoidal, Balanced, or Unbalanced Conditions," IEEE Std 1459-2010, pp. 1-50, 2010.

[3] P. G. Axelberg, I. Gu and M. H. Bollen, "Support vector machine for classification of voltage disturbances," Power Delivery, IEEE Transactions on, vol. 22, pp. 1297-1303, 2007.

[4] J. Driesen, T. Van Craenenbroeck, R. Reekmans and D. Van Dommelen, "Analysing time-varying power system harmonics using wavelet transform," in Instrumentation and Measurement Technology Conference, 1996. IMTC-96. Conference Proceedings. Quality Measurements: The Indispensable Bridge between Theory and Reality., IEEE, 1996, pp. 474-479.

[5] Y. H. Gu and M. H. Bollen, "Time-frequency and time-scale domain analysis of voltage disturbances," Power Delivery, IEEE Transactions on, vol. 15, pp. 1279-1284, 2000.

[6] S. Santoso, E. J. Powers and W. Grady, "Power quality disturbance data compression using wavelet transform methods," Power Delivery, IEEE Transactions on, vol. 12, pp. 1250-1257, 1997. 
[7] L. Angrisani, P. Daponte, M. D'apuzzo and A. Testa, "A measurement method based on the wavelet transform for power quality analysis," Power Delivery, IEEE Transactions on, vol. 13, pp. 990-998, 1998.

[8] W. G. Morsi and M. El-Hawary, "A new perspective for the IEEE Standard 1459-2000 via stationary wavelet transform in the presence of nonstationary power quality disturbance," Power Delivery, IEEE Transactions on, vol. 23, pp. 2356-2365, 2008.

[9] W. G. Morsi and M. El-Hawary, "Wavelet packet transform-based power quality indices for balanced and unbalanced three-phase systems under stationary or nonstationary operating conditions," Power Delivery, IEEE Transactions on, vol. 24, pp. 2300-2310, 2009.

[10] M. Zhang, K. Li and Y. Hu, "A real-time classification method of power quality disturbances," Electr. Power Syst. Res., vol. 81, pp. 660666, 2011.

[11] W. A. Ibrahim and M. M. Morcos, "Artificial intelligence and advanced mathematical tools for power quality applications: a survey," Power Delivery, IEEE Transactions on, vol. 17, pp. 668-673, 2002.

[12] M. K. Saini and R. Kapoor, "Classification of power quality events-a review," International Journal of Electrical Power \& Energy Systems, vol. 43, pp. 11-19, 2012.

[13] A. K. Ghosh and D. L. Lubkeman, "The classification of power system disturbance waveforms using a neural network approach," Power Delivery, IEEE Transactions on, vol. 10, pp. 109-115, 1995.

[14] C. Dilokratanatrakool, P. Na Ayudhya, T. Chayavanich and C. Prapanavarat, "Automatic detection-localization of fault point on waveform and classification of power quality disturbance waveshape fault using wavelet and neural network," in Robotics, Intelligent Systems and Signal Processing, 2003. Proceedings. 2003 IEEE International Conference on, 2003, pp. 142-147.

[15] D. Srinivasan, W. Ng and A. Liew, "Neural-network-based signature recognition for harmonic source identification," Power Delivery, IEEE Transactions on, vol. 21, pp. 398-405, 2006.

[16] K. Silva, B. Souza and N. Brito, "Fault detection and classification in transmission lines based on wavelet transform and ANN," Power Delivery, IEEE Transactions on, vol. 21, pp. 2058-2063, 2006.

[17] N. Huang, D. Xu, X. Liu and L. Lin, "Power quality disturbances classification based on S-transform and probabilistic neural network," Neurocomputing, vol. 98, pp. 12-23, 2012.

[18] G. Heydt and A. Galli, "Transient power quality problems analyzed using wavelets," Power Delivery, IEEE Transactions on, vol. 12, pp. 908-915, 1997.

[19] I. Daubechies, Ten Lectures on Wavelets. SIAM, 1992.

[20] M. Uyar, S. Yildirim and M. T. Gencoglu, "An effective waveletbased feature extraction method for classification of power quality disturbance signals," Electr. Power Syst. Res., vol. 78, pp. 1747-1755, 2008.

[21] A. Gaouda, M. Salama, M. Sultan and A. Chikhani, "Power quality detection and classification using wavelet-multiresolution signal decomposition," IEEE Trans. Power Del., vol. 14, pp. 1469-1476, 1999.

[22] IEEE Standards Association, "1159-2009. IEEE Recommended Practice for Monitoring Electric Power Quality Industrial and Commercial Applications," 2009. 